\title{
Construction of Student Societies in View of the Education of Chinese Excellent Traditional Culture
}

\author{
Kai Lu ${ }^{1}$ \\ The Youth League Committee \\ Dalian University of Technology, DUT \\ Dalian, P. R. China \\ e-mail:lukai@dlut.edu.cn
}

\author{
Yi Wang ${ }^{2}$ \\ Student Office \\ Dalian University of Technology, DUT \\ Dalian, P. R. China \\ e-mail:wangyee@dlut.edu.cn
}

\author{
Lifang Feng ${ }^{3}$ \\ The Youth League Committee \\ Dalian University of Technology, DUT \\ Dalian, P. R. China \\ e-mail:fenglifang@dlut.edu.cn
}

\begin{abstract}
Based on the education perspective of Chinese excellent traditional culture, qualitative research methods are applied to further cultivate and practice the socialist core values in college, and construct college student societies as an important carrier of culture heritage. The features of societies in spreading excellent traditional culture are analyzed deeply. Suggestions are put forward to develop the college student societies on the basis of fully exploring the construction of the existing societies. The management and protection mechanisms are further improved to promote the development and construction of societies, as well as the inheriting and development of the traditional culture.
\end{abstract}

Keywords-Chinese excellent traditional culture; College student societies; Cultural communication

\section{INTRODUCTION}

Views on the cultivation and practice of the socialist core values clearly states that it is necessary to take advantage of the important effect of traditional culture on edifying sentiment and the nourishing civilization. Universities as the important occasion of the ideological and political education and the spread of advanced culture, have the characteristics of focused audience, diverse publicity carrier. It has important and far-reaching significance to make full use of the advantages of universities to popularize the essence of traditional culture, (and) promote the scientific development concept among college students. In recent years, with the deepening of reform of higher education, and the changes of learning and life styles of college students, more and more student societies have been welcomed by the majority of the students, (which) providing a good platform on the prosperity and development of the campus culture and college ideological and political education. Student Societies with distinctive theme, broad participation groups and rich forms of activities, play a major role in spreading Chinese excellent traditional culture in universities. By analyzing the nature, characteristics and function of the student societies, this paper summed up the main advantages of societies in spreading Chinese excellent traditional culture, analyzed the current development of societies, summarized the factors restricting the development of societies and proposed the base path and specific measures to propagate excellent traditional culture via societies. It plays an important role in guiding further exploration of the effective communication ways for Chinese excellent traditional culture.

\section{Features and Functions for College Student Societies IN VIEW OF THE EDUCATION OF CHINESE EXCELLENT TRADITIONAL CULTURE}

College student societies have a history of more than one hundred years, since the earliest college student society was founded in 1904 in Peking Imperial University called AntiRussia Ironic Blood Society. The early societies are autoorganized by young students who wanted to save the countries through the forms of assembly, speech, parades, etc. [1] Subsequently, the student societies in China are booming. In the 100 years' history, the college student societies are closely linked with the change of the time and play an important and active role in the tide of the new democratic revolution.

With the development of history, college student societies gradually develops into an important form for college students to attend cultural activities at leisure time. College student societies are defined as a kind of student organization which is established voluntarily based on common interests, hobbies, strengths of the students and approved by the authority of college. ${ }^{[2]}$ Also, the members of them should obey the related regulations in the 
college. With the development of our economy and society, college student societies are springing up and flourishing, it is playing an important role in the various aspects of the college students such as education, management, life, entertainment, etc. As an effective carrier of the campus culture, it is developing into a broad platform for college students to improve their comprehensive quality. College student societies are taken as the object of the study, which defined as communities where a group of students who have common hobbies or expertise and come together voluntarily. There are various student organizations to conduct activities associated with spreading and inheriting the traditional culture on the basis of unified authentication and management of the school. College student societies of traditional culture are popular among students for their unique cultural concept of societies and forms of activities, forming a prosperous university campus culture as a place to promote the cultivation for the elitist. The societies forms its own characteristics in their development process, and plays an active role in the construction of college campus.

\section{A. Features of the College Student Societies}

College student societies are with the feature of autonomy in various activities and conduct auto-education, auto-management and auto-service. Just because of the auto-organization of students, they are extensively affected by the cultural structure, scope of activity and organization forms of their members. The features of the societies of traditional culture are mainly displayed as following:

Firstly, the establishment of the societies is based on the spontaneity of students. Under the management and guidance of the specific authority, college student societies of traditional culture are established on the basis of the interests and specialty of students themselves and the organizer or the person in charge voluntarily undertake the duty of organization and management. Moreover, the members of the societies have a consensus based on their common interests, hobbies and ideas in the community and voluntarily participate in the activity.

Secondly, the society activities take on the connotation of the traditional culture. Based on the appeal and attractiveness of traditional culture among college students, some society activities highlight to inherit and carry forward the traditional culture considering the connotation of Chinese traditional culture. Meanwhile, part of the societies focus on the popularity of traditional culture among teachers and students, including the popularity of traditional poetry, traditional costumes, traditional etiquette, etc., focusing on the manifestation of the cultural connotations.

Thirdly, the participants of societies are extensive. Chinese traditional culture is profound, so a wide variety of societies are built up to include almost all aspects of traditional culture. Due to the comprehensiveness of the societies of traditional culture, young students can choose societies based on their extensive interests and hobbies. Meanwhile, societies tend to attract more students in different grades, disciplines and gender to participate, with a broad mass base.

Finally, the forms of society activities are various. The forms of activities is diverse due to the various types of traditional cultures are involved. Meanwhile, the creative ideas from highquality and high-ability students can attract students to participate for their novelty. In addition, highlighting the characteristics of diversity and flexibility, the activity forms of societies are not restricted by college. Under the laws, a wide range of activities can be conducted in the form of speeches, competitions, seminars, exchanges, etc.

\section{B. Functions of the College Student Societies}

College student societies have developed into an effective carrier to enhance the comprehensive quality of students and prosper campus culture, which mainly reflects in the following areas.

Firstly, function as ideological and politic education. Through developing a variety of cultural activities and extending the Chinese traditional culture, the college student societies help the young students to build a socialist core value system, and promote the national spirit and the traditional cultural identity and pride of the members, further cultivating the patriotic youth. [3] At the same time, through the radiation effects of community members, the societies spread patriotism-centered national spirit and the traditional culture as the core of the country's culture to more young students. The interaction between societies and members can subtly pass the concept and content of ideological and political education to the members, and thus affect their way of thinking and behavior and extensively function as radiation.

Secondly, function as the creation and inheriting of campus culture. The formation of college campus culture in large part is due to the extensive development of cultural activities on campus. College student societies focus more on the campus cultural activities, which play a creative role in the campus culture. Meanwhile, the societies make traditional culture heritage injected new vitality by conducting innovative and active activities to promote the continuation of traditional culture ideas, and the heritage of spirits.

Thirdly, function as improving students' culture idea and quality. The influence of College student societies of on the young students cannot be ignored, for that most of the students' knowledge of traditional culture and the understanding of the values is obtained through the campus activities of societies. A variety of societies of traditional culture play a subtle role in enhancing students' comprehensive quality, aesthetic taste, perfecting students' mind and their personality.[4]

Fourthly, function as maintaining the harmonious atmosphere in campus. The activities conducted by college student societies, attract students to participate extensively and make students' after-school life colorful due to their rich content and diverse forms. Moreover, they allow students to learn more about social development and school construction, forming a more 
harmonious, democratic campus atmosphere, sharing the vision of being patriotic and loving school and facilitating the long-term harmonious construction of the college.

\section{Current Statuses of College Student Societies IN VIEW OF THE EDUCATION OF CHINESE EXCELLENT TRADITIONAL CUlture}

At present, college student societies have been developed in all the colleges and universities. The number of such societies is increasing year by year. More influential societies are established, such as May Fourth Literary Society of Peking University, Tsinghua University Literary Society and so on. College student societies on traditional culture carry out various types of activities to extend and develop the concept and connotation of the traditional culture. These activities attract the majority of teachers and students to participate, greatly enriching the students' extracurricular and cultural life. The development of societies of traditional culture has begun to take shape and has influences in the universities. However, as college student societies are flourishing, the development of them is still faced with some problems, such as the insufficiency of their management mechanism and security mechanism.

\section{A. Insufficient effectiveness of society management and operation machanism}

Most of the college student societies are managed under the Communist Youth League of the school. However, the Communist Youth League itself is occupied by lots of affairs. As a small part of its affairs, society work is often difficult to be treated specifically. Due to the low pertinence and effectiveness, the bloom of societies cannot be formed. [5] At the same time, the orientation of the societies in some school is vague. The establishment and operation of the societies are lack of effective management. These societies are difficult to be advanced and branding. With the imperfect management and guidance mechanism the societies cannot play a positive role during the construction of campus culture.

\section{B. Lack of Funding to Operate the Societies}

At present, the lack of funding is the main factor to restrict the college student societies in most college to grow bigger and stronger. At present most of the founding comes from college Youth League or the school expenditure for student activities, as well as the membership fees and corporate sponsorship.[6] Among them, the school funding and membership fees is limited, so it is difficult to meet the day-to-day expenditure for the activities of college student societies. Let alone of the distinctive and influential activities. The corporate sponsorship is not easy to obtain, because students have not enough experience or energy and sometimes the requests from the corporate and the regulation in the college are conflict. The loss of the channels of corporate sponsorship cuts the funding, leads to the difficulty of the organization of many society activities.

\section{Lack of Instructor to Guide the Societies}

With the vigorous development of the societies, the lack of the guidance for the societies has become increasingly prominent. The guiding forces, in some colleges, usually consist of school counselors and retired teachers, they are insufficient to fully cover all the societies. Meanwhile, the request for the teachers guiding societies is higher than other societies, so the composition of the guidance teachers need to be further updated and a large number of professional and high-quality teachers are in need. [7] The lack of the guiding force for the societies is a serious impediment to the development of the societies and negative for their various functions.

\section{Instability of the Student Societies}

From the internal perspective of societies, some societies easily lead to the loose management of the society, unclear work distribution and vague financial issue due to the lack of the necessary rules and regulations, which can directly affect the normal societies activities. This phenomenon results in the anticlimax and negative effects of some student societies. The annual registration rate of societies of is higher than other student communities, but the frequency of community activities and the impaction is not advantageous. The uncertainty of the internal organizational structure and the organizing principle is also a great influential factor.

\section{Suggestions and StRategies on the Construction of STUdent Societies in View of the EdUCATION OF Chinese EXCELLENT TRADITIONAL CULTURE}

The development of college student societies is in the ascendant, it plays a crucial role in the prosperity of the college campus culture, and promotes university elitist training, and enhances the dissemination of the concept of conservation culture. Faced with the problems and constraints existing in the development of the college societies, the essay is starting from the spread of the concept of conservational culture, combined with the current development of college societies, put forward further strategies and suggestions, and to explore effective ways to disseminate the concept of conservational culture.

\section{A. Improving the Security Mechanism and Strengthening the Construction of Political Parties and other Organizations}

Youth Federal Report [2005] No.5 the Central Committee of the Communist Youth League, Ministry of Education views on strengthening and improving university students' social work clearly states: "To actively explore and promote to establish party organization and league organization in the college student societies to strengthen the political guidance of them their political guidance and incorporate effective ideological and political education into community activities, Make the student societies play a better role in the ideological and political education for college students." For a wide variety of student societies with features such as diverse professions, high degree of freedom and so on, it is necessary to further promote the 
construction of internal caucus of societies and strengthen the norm and guidance of the internal mainstream thought. Bringing the party or league organization into societies can be further applied to the coordinated development of party building and the group building and guide members to establish a correct understanding of traditional culture in the concept of conservational culture, and also enhance the effectiveness of such societies. Through the establishment of such regulations, not only can promote the unification of traditional culture and Marxist outlook on life, but also arouse their internal vitality of societies. The continuous cultivation of high-quality members is an important way to make the college societies on traditional culture a critical flat to spread the concept of conservation culture.

\section{B. Strengthening the Professional Guidance and Upgrade the Level of Societies}

Societies are often very professional, (.) To maintain and enhance the professional quality of such societies and to gradually strengthen members' understanding of traditional conservational culture theory and understanding its essential importance of the dissemination of conservational culture are (both) crucial. To strengthen and improve the professional quality of the instructors is a better way to incorporate the society work into the evaluation of them, to improve their sense of responsibility to the society work. Providing professional training to the members and enhancing the learning and exchange through the internal discussion and advanced class are great ways to spread the traditional culture on campus. Identify the orientation of the traditional culture community and further highlight the relevance and timeliness of the ancient Chinese civilization and guide the societies on traditional culture to be branding. While improving professional quality of the societies, upgrade the level and standard of community activities, strengthen the effectiveness of the activities and timing, and enhance the coverage and appeal of activities, as well as make the cultural connotation and spiritual essence of the activity rich. The active form should be decided combined with contemporary characteristics of college students, instead of blindly preaching and indoctrination, devoting us to conducting branding activities, which is the combination of education, entertainment and knowledge.

\section{Providing Aids and Offering Support of Funding}

The college community authorities should first affirm that the societies of traditional culture play a crucial role in the dissemination of the traditional concept of conservational culture, and realize that the guiding effects and disciplining function for the daily behavior of other college student societies. At the same time, the school party committee should regard the construction of such societies as a special work, coordinated with Student Affairs Office, Office of Academic Affairs, Youth League and the annual budget of the departmental working to favor them from the organization, from a policy, from the large funding to provide a relaxed external environment for the development of societies. Meanwhile, the funding supply should be done. For instance, setting up the account for some special activities for the dissemination of the traditional concept of conservational culture and supporting to organize special events by Monthly Activities or Theme Learning Classes in each school year to spread the concept of harmonious development into the world. At the same time, according to the current situation in the college and the law of the development of society activity, effective ways should be explored to spread the concept of conservational culture. And finally a long-term and wide-range plan should be made, regular conclusion, report and evaluation should be conducted, and form a incentive mechanism to reward the outstanding organization and individual.

\section{Strengthening the Management and Service to Guaranteeing the Stability of the Societies}

It is a better way to strengthen the effectiveness of the joint management and service coordination of student societies, develop the way of thinking from the daily experiences and upgrade the societies of traditional culture into a new stage. The approval of the societies on traditional societies should be rigid and the examination of the regulations, rules, validity, direction and objective of activities can't be too careful. Only when it is really needed according to the current situation in college can a society be approved. To gradually perfect the mechanism in the societies, incentive mechanism should be clear and rewards should be given to the outstanding organization and individuals including funding support. Usually a report should be made by the outstanding ones to set good examples for others. However, the ones which are plain in achievements and slowly developed should be warned or punished. If it is not changed to a good status in a limited time, the society should be cancelled or incorporated by the likes. The cultivation of the main members in the society is crucial. We should help them to well recognize the situation, enhance their professional knowledge and improve their level. Selection mechanism should be viewed a lot. The cultivation of the high-quality, high-ability and high-prestige leader of the society is an easy way to mould the others. The creative thinking is encouraged inside the societies for that it is a way to find out the carrier and approach to spread the concept of conservational culture in societies on traditional culture and, meanwhile, realize the function the development of quality, the conversion of outcomes and unification of individual strength.

\section{REFERENCES}

[1] Lv Chunhui. Development Changes and Thought of Chinese College Student Societies[J]. Jilin: Changchun University of Technology, 2012,33(1):88-91. (In Chinese)

[2] Zhang Lixia, Chen Jianhua, Hu Zhenghao. The Study of Characteristics and Functions of College Student Societies[J]. Hubei: Party Building and Ideological Education at School, 201 1,(33):72-73. (In Chinese)

[3] Liu Qingjie. The Analysis of the Fuctions of College Student Societies in View of Political Education [J]. Beijing: Beijing Polytechnic College, 2013,12(2):57-60. (In Chinese)

[4] Li Xue,Yu Ying.Construction of College Students' Association[J]. Journal of education institute of Jilin,2014,30(3):28-29. (In Chinese) 
[5] Zhang Faping. Problems and Solutions of the Construction of College Student Societies[J]. Zhejiang: Zhejiang Ocean University, 2010,27(2):115-117. (In Chinese)

[6] Zhu Hongnan,Zhang Han,Yu Chongxin.Thoughts and Suggestions for College Students' association —-Based on an Empirical Study of 17 colleges in Liaoning Province, [J].2014(9):80-81. (In Chinese)
[7] Wang Chunwei,Wang Mingfeng.The problems and the Path of Development in the college students' association [J].Education Teaching Forum,2014(8):122. (In Chinese) 